\title{
MIIR Teaching Model Construction under Information Technology Environment
}

\author{
Haiyun Zhang, Lu Zhao \\ Department of Information Technology, Northeast Normal University, Jilin Province, China \\ zhanghy545@nenu.edu.cn, zhaol638@nenu.edu.cn
}

\begin{abstract}
To solve the problems of little vocabulary, lack of interest and no innovation in the primary Chinese writing teaching, attempting to design and build MIIR (Motivation, Inquiry, Reflection and Reflection) teaching model in this paper.
\end{abstract}

Index Terms - Teaching model. Information technology environment. MIIR.

\section{Introduction}

\section{A. The Research on MIIR Teaching Model}

MIIR is the abbreviation for Motivation (interest motivated teaching), Inquiry (cooperative inquiry), Innovation (innovation exchange) and Reflection (summarize and reflection). As everyone knows, "interest is the best teacher", then in order to help students learn a course better and master a skill better during the teaching, it should be known that the interest motivation teaching would be the premise, the cooperative inquiry would be the core way, innovation exchange would be the objective and the summarize and reflection would be the key role.

Taking interest motivation teaching as the premise, students' curiosity would be motivated, and the nonintellectual factors such as learning motivation, learning interest, learning attitude, willpower and confidence would be motivated. The cooperative consciousness, team spirit, expressing ability and inquiry spirit of students would be cultivated by cooperative inquiry method. In addition to that, interaction between a teacher and students, students and students, students and teaching materials would be strengthened. Innovation exchange is the final teaching objective which is promoted by the new course reform. Summarize and reflection would be the key factor that decides whether the teaching is succeeded. The teacher and students summarize the teaching process together, and keep on reflecting the understanding and mastery degree of learning content.

In order to put the idea of transforming traditional teaching concept which is promoted by the new course reform into effect, as well as to change the old teacher-centered teaching structure, to optimize teaching process, to cultivate questioning consciousness, divergent thinking and innovation ability of students, the MIIR teaching model has been conceived in this paper.

\section{B. Theoretical Basis \\ 1) Constructivism Learning Theory}

Constructivism is the development of behaviorism in learning theories. It has been a revolution of learning theory of the time, and the key theoretical basis of networked teaching model construction. A teacher-leading and students-centered teaching model has been emphasized by constructivism learning theory. To students, during the teaching process, a teacher is not only their mentor, helper and director, but also a good partner in life. The importance of meaning construction on situation has also been emphasized. Today, network technology has been rapidly developed. With the help of network technology, a wonderful, visualized and flexible teaching situation could be created. This situation would help to cultivate the curiosity, divergent thinking and questioning consciousness of students. In addition to this, cooperative learning, situation design, meaning construction and the effective use of teaching resources have been also emphasized in constructivism.

From the above, MIIR is a teaching idea which is based on constructivism and takes teachers as leadership, students as main body. . This model can fully reflect the leading role of a teacher and the dominant role of students; besides to that, it can also create a harmonious, free and comfortable learning environment for students.

\section{2) Humanism Learning Theory}

Humanistic psychology is a trend of psychological thought which rose at the USA in 1950s. The mean representative figures are A.Maslow and C.R.Rogers. Humanism believes that just like every seed sprouts toward sunshine, we should know every human has a positive conscious, and the self-actualizing impulsion to grow up and release potential abilities. It advocates the idea of studentcentered and let students learning under a free easy environment. The basic principle is that the research object of psychology is human; the research emphasis of psychology should focus on the intercommunity such as the selectivity, creativity, values and self-actualization; concern on human value and dignity, to release human potential abilities; pay attention to individuality and subjectivity of human.

The research object of MIIR is the students of primary school. This model is based on the respect of value and dignity of individual, aim to cultivate the cooperative inquiry and innovation ability of students, with a view to give full play to internal potential of individual and to achieve self-worth.

\section{Preparation}

Because no matter a traditional teaching model or a new teaching model, teachers and students cannot be put aside. As MIIR should be preceded in network technology environment, so the hardware and software support should be needed.

Hardware devices which with reasonable size, including CCTV System (Closed Circuit Television System), two-way control multimedia teaching system, audio-visual classroom, 
network computer room, multimedia teaching platform monitoring system and electronic audio-visual reading room.

In this information age, the training of teaching staff is indispensable. Nowadays, this training has to include not only basic information quality, but also high professional quality. The reason is that only the teacher with high professional quality can be a helper, director and mentor during the teacher-centered student-oriented teaching process.

The preparation of students should also be critical, especially the information quality of students. A higher information consciousness, knowledge and morality should be required in information technology environment. With the development of information technology and the popularity of digitized campus, the information consciousness of students has been improved. However, the cultivation of information qualification of students cannot accomplish in an action, it largely needs helps and guidance by teachers. The teacher should give different and timely directions according to the difference of characters, cognitive traits and ability levels among different students. In this way, students would grasp a learning content comprehensive and systematic, a higher information quality would be cultivated and the learned knowledge would be used flexibly. Besides that, consciousness and spirit of innovation would be generated.

\section{MIIR Teaching Model Construction}

\section{A. MIIR Teaching Model Diagram}

MIIR reflects the leading role of a teacher and the principal role of students. The final purpose is to cultivate the question consciousness, creative ability and cooperative exchange ability of students. It has been made up by three parts: teacher activity, teaching procedure and student activity. Teacher activity means the inducing, direction, help and instruction during teaching progress. Student activity means to motivate students' interest, cultivate curiosity, divergent thinking, migration of knowledge and meaning construction. The most important point, is the design of indispensable teaching procedures of a lesson. The teaching procedures are Motivation (interest motivation teaching), Inquiry (cooperative inquiry), Innovation (Innovation exchange) and Reflection (Summarize and Reflection).As shown in figure 1.

\section{B. Analyze of MIIR Teaching Model Diagram}

The MIIR teaching model under information technology environment suits for writing teaching of primary school Chinese. This model includes four steps: Motivation (interest motivation teaching), Inquiry (cooperative inquiry), Innovation (Innovation exchange) and Reflection (Summarize and Reflection).

\section{1) Interest Motivation Teaching}

Normally, during the traditional Chinese writing teaching, students write an article with difficulty: little vocabulary and with no interest on writing, just finish it to meet the homework. As a result, the article is low quality, with no creativity and lots of stupid mistakes. The procedure of interest motivation teaching in MIIR can avoid these problems well. It can motivate the interest of students on Chinese writing, and create a visual, wonderful, flexible and novel situation, immersion atmospheres for students. There are plenty of different interest motivation teaching methods.

Technology Motivation: use multimedia technology, information technology and network technology to motivate students' interest.

Situation Motivation: create situation to active classroom climate. It makes teaching process visualization, teaching content informatization.

Words Motivation: design proper questions and suspense to motivate students' interest.

Game Motivation: play games to motivate students' interest and curiosity.

Activity Motivation: set various kinds of teaching activities, let students positive participate in the teaching activity to motivate interest and improve teaching efficiency.

These methods can be chosen by different writing contents and students' characters.

\section{2) Cooperative Inquiry}

Cooperative means work in coordination to complete one work together. Inquiry is a process that students exchange and check their answers which obtained by observing, reading discovering questions and collecting data. The cooperative inquiry in teaching is that in order to complete one teaching task or achieve the same goals, students cooperate and exchange with each other during teaching process.

In the information technology environment, students can cooperate and inquiry with the help of information technology. Students involve to the whole teaching process, they can collect materials, inquiry writing contents by groups. They should communicate with teachers timely, and teachers could organize and direct students to inquiry. Thereby the writing inquiry ability would be cultivated.

\section{3) Innovation Exchange}

In the traditional teaching, there is little communication between students and teachers, students and students, students and teaching contents. Teaching efficiency is low and cannot achieve the goal of two-way activity between teachers and students which required in new curriculum standard. The creative spirit and ability of students cannot be motivated by the uninteresting teaching which lacks of communication and exchange. The Chinese writing teaching under information technology environment could enhance the communication not only between students and the teacher but also between students and students. Students can search and collect materials on internet according to the writing content, then communicate these materials with other students and summarize them together. In this way, the little vocabulary, lots mistakes and old ideas articles can be avoided. This method can also contribute to create higher quality articles with novel vocabularies, smooth sentences and creative ideas.

\section{4) Summarize and Reflection}

The Summarize under information technology environment is proceeding by both teachers and students. The teacher directs students and leads them to review the knowledge learned in a lesson, according to the participation of activities, the behavior during class, the cooperation during communication. Students can adopt either "Slade Share" 
platform to summarize and reflect or "Mind-manager" to draw the knowledge tree.

This article has proved that compare to traditional teaching model, MIIR model in information technology environment, the interest to writing of students has been improved, ability of expression, collaborative inquiry, innovation and reflection has been cultivated, and communication between teacher and students has been enhanced. Thereby, it can be sure that during the teaching process, interest motivation teaching would be the premise, cooperative inquiry would be the core way, innovation exchange would be the objective and summarize and reflection would be the key role.

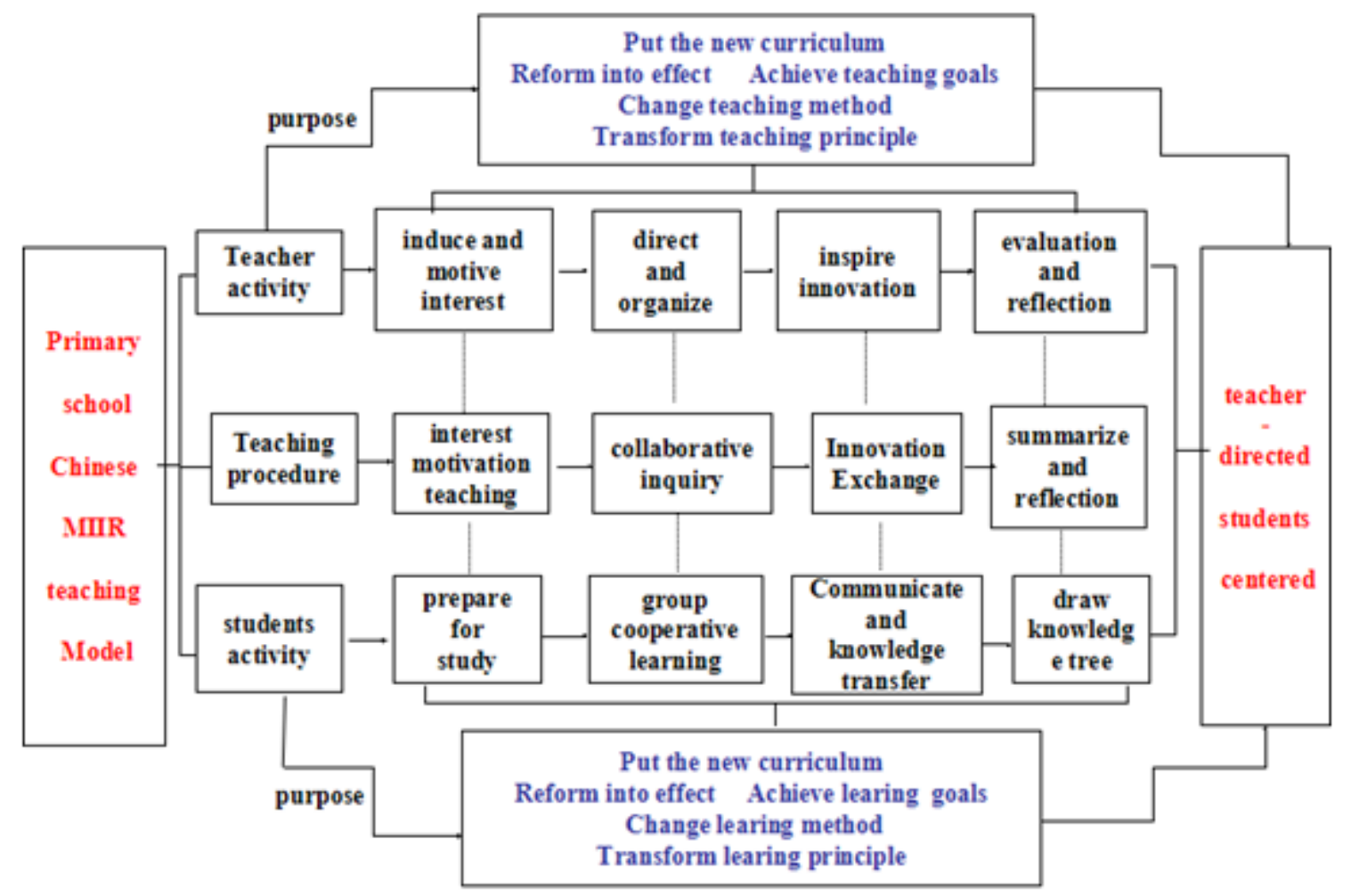

Fig. 1 MIIR Teaching Model Diagram

\section{Acknowledgment}

My deepest gratitude goes first and foremost to my teacher Doctor Li .I also owe my sincere gratitude to my friends and my fellow classmates who gave me their help and time in listening to me and helping me work out my problems during the difficult course of this paper.

\section{References}

[1] Chunlin Song, "The construction of Chinese teaching mode under the network environment," East China Normal University, 2007.
[2] Kekang He, "information technology and curriculum theory deep integration", Beijing Normal University press, 2008.

[3] Xianli Liu, "The application of junior middle school English reading teaching mode under the network environment", Central China Normal University, 2008.

[4] Application of science, Law to discuss, 2012.

[5] Xiangping Zhong, "Motivation method during in the Junior middle school language classroom teaching shallow exploration”, Hunan Normal University, 2011. 